\title{
Astragalus polysaccharide protects human cardiac microvascular endothelial cells from hypoxia/reoxygenation injury: The role of PI3K/AKT, Bax/Bcl-2 and caspase-3
}

\author{
LIANDI XIE ${ }^{1}$, YANG WU ${ }^{1}$, ZONGJING FAN ${ }^{1}$, YANG LIU $^{1}$ and JIXIANG ZENG ${ }^{2}$ \\ ${ }^{1}$ Department of Cardiology, Dongfang Hospital of Beijing University of Chinese Medicine, Beijing 100078; \\ ${ }^{2}$ Department of Cardiology, Beijing University of Chinese Medicine, Beijing 100029, P.R. China
}

Received June 3, 2015; Accepted April 20, 2016

DOI: $10.3892 / \mathrm{mmr} .2016 .5296$

\begin{abstract}
In the present study, the mechanisms associated with the Astragalus polysaccharide (APS)-mediated protection of human cardiac microvascular endothelial cells (HCMEC) against hypoxia/reoxygenation (HR) injury were investigated. Pretreatment of HCMECs with APS at various concentrations was performed prior to $\mathrm{Na}_{2} \mathrm{~S}_{2} \mathrm{O}_{4}$-induced HR injury. Subsequently, cell viability and apoptosis were measured by MTT and Hoechst assays, respectively. The viability of HCMECs was reduced by $\mathrm{Na}_{2} \mathrm{~S}_{2} \mathrm{O}_{4}$ and apoptosis was enhanced; however, cell viability was observed to be increased by APS via inhibition of apoptosis. Additionally, intracellular reactive oxygen species (ROS), $\mathrm{Ca}^{2+}$, nitric oxide (NO), malondialdehyde (MDA), superoxide dismutase (SOD), phosphatidylinositol 3-kinase (PI3K)-protein kinase B (AKT), B-cell lymphoma-2 (Bcl-2), Bcl-2 associated $\mathrm{X}$ protein (Bax) and caspase-3 were measured using detection kits or western blot analysis. In HCMECs with HR injury, the levels of ROS and $\mathrm{Ca}^{2+}$, MDA and Bax expression levels, and the activity of caspase-3 were elevated. By contrast, the level of NO, the protein expression levels of SOD, Bcl-2 and PI3K, and the phosphorylation of AKT were decreased. However, compared with the HR group, the effects of HR injury were significantly reduced by APS, with APS providing a protective effect on HCMECs, particularly at higher doses. The current study concluded that APS protects HCMECs from $\mathrm{Na}_{2} \mathrm{~S}_{2} \mathrm{O}_{4}$-induced HR injury by reducing the levels of ROS, $\mathrm{Ca}^{2+}$, MDA and Bax, inhibiting the activity of caspase-3, and enhancing the levels of NO, SOD, Bcl-2, PI3K and phosphorylated AKT. These results may provide an insight into the clinical application of APS and novel therapeutic strategies for HR injury.
\end{abstract}

Correspondence to: Dr Liandi Xie, Department of Cardiology, Dongfang Hospital of Beijing University of Chinese Medicine, 6 Fangxingyuan 1 Qu, Beijing 100078, P.R. China

E-mail: xieliandidh@163.com

Key words: Astragalus polysaccharide, human cardiac microvascular endothelial cells, hypoxia/reoxygenation, cell apoptosis, signaling pathway

\section{Introduction}

A monolayer of vascular endothelial cells (VECs) acts as a physiological barrier between blood vessels and vascular tissues; this monolayer maintains the integrity of the vascular wall and the function of blood circulation. Ischemia/reperfusion injury of important organs, including the heart, brain and kidneys, causes severe damage to VECs and increases the production of reactive oxygen species (ROS) (1). ROS act as important intracellular messengers, inhibiting the protein kinase B (AKT) and mitogen-activated protein kinase 1 signaling pathways, and directly inducing cell apoptosis $(2,3)$. ROS also affect the phosphatidylinositol 3-kinase (PI3K)-AKT signaling pathway, which activates or inhibits downstream target proteins, including B-cell lymphoma 2 (Bcl-2), Bcl-2 associated $\mathrm{X}$ protein (Bax) and caspase-3, via phosphorylation, and regulates various biological functions, including cell growth, proliferation, adhesion and apoptosis (4). Additionally, the changes to cell metabolism and apoptosis caused by ROS are important factors in cardiovascular dysfunction (5). Thus, the regulation of ROS-associated pathways may be an important mechanism for the protection of VECs.

Radix Astragali is the dried root of the leguminous plant Astragalus membranaceus (Fischer) Bge. var. mongolicus (Bge.) Hsiao. According to traditional Chinese medicine, Radix Astragali demonstrates efficiency in tonifying Qi to reinforce Yang, strengthening superficial resistance, promoting urination to expel internal toxins/pus, promoting tissue regeneration and improving the healing of sores; therefore, it is an important and commonly used traditional Chinese medicine for strengthening healthy energy and tonifying Qi (6). Astragalus polysaccharide (APS) is the primary active ingredient of Radix Astragali and previous studies have demonstrated it to have a variety of pharmacological effects. APS reduces the damage to VECs caused by hypoxia/reoxygenation (HR) and reperfusion injury of human cardiac microvascular endothelial cells (HCMECs) $(7,8)$. In particular, A-3, a component of APS, may protect the function of VECs from damage induced by paraoxon, which is associated with increased superoxide dismutase (SOD) and decreased malondialdehyde (MDA) levels (9). Additionally, the combined use of Radix Astragali and ligustrazine significantly protected VECs by elevating nitric oxide (NO) release (10). Radix 
Astragali also inhibited endothelial cell apoptosis induced by advanced glycation end products via the downregulation of ROS levels (11). A previous investigation indicated that APS may suppress HR-induced damage to HCMECs damage by alleviating the oxidative stress caused by ROS and increasing NO levels. Additionally, APS was demonstrated to activate the PI3K-AKT-endothelial NO synthase (eNOS) signaling pathway, thus promoting the proliferation and differentiation of endothelial progenitor cells in the peripheral blood of patients with type 2 diabetes (12). APS also inhibited the apoptosis of HCMECs induced by oxygen and glucose deprivation, with the effects potentially mediated by changes in AKT phosphorylation levels (13). Additionally, it was previously demonstrated that APS potentially protects HCMECs from HR injury via regulation of the PI3K-AKT signaling pathway.

Thus, the present study aimed to investigate whether APS protects HCMECs from HR-induced injury via inhibition of ROS-induced oxidative stress and cell apoptosis, and if APS alters the regulation of the PI3K-AKT pathway, using an HCMEC model of HR-induced injury.

\section{Materials and methods}

Materials and cell culture. APS was purchased from Nanjing Zelang Medical Technology Co., Ltd. (Nanjing, China). A bicinchoninic acid (BCA) assay kit, caspase-3 assay kit, 2',7'-dichlorofluorescin diacetate (DCFH-DA) probe, Fura-2/AM probe and Hoechst apoptosis kit were purchased from Beyotime Institute of Biotechnology (Shanghai, China). Methylthiazolyl tetrazolium (MTT) was purchased from Gibco (Thermo Fisher Scientific, Inc., Waltham, MA, USA). Rabbit anti-human monoclonal antibodes: AKT (cat. no. 1063-1), Bax (cat. no. 1017-1), Bcl-2 (cat. no. 1080-1), phosphorylated-AKT (p-AKT; cat. no. 5508-1), PI3K (cat. no. 1683-1) and GAPDH (cat. no. 5632-1) were provided by Epitomics (Burlingame, CA, USA). SOD, MDA and NO assay kits were purchased from Nanjing Jiancheng Bioengineering Institute (Nanjing, China; cat. nos. A001-1, A003-1, and A012, respectively). $\mathrm{Na}_{2} \mathrm{~S}_{2} \mathrm{O}_{4}$ was obtained from Aladdin Reagent (Shanghai) Co., Ltd. (Shanghai, China).

HCMECs were purchased from ScienCell Research Laboratories (Carlsbad, CA, USA). The cells were incubated with rabbit anti-human polyclonal anti-factor VIII [cat. no. bs-0434R; Shanghai Kemin Biotech Co., Ltd. (Shanghai, China)] and anti-CD31 (cat. no. BA1346; Wuhan Boster Biological Technology, Ltd., Wuhan, China) antibodies, and Dil-acetylated low-density lipoprotein (Sciencell Research Laboratories) to confirm their endothelial phenotype. The protocol and characterization were performed according to a previous study (14). The cells were cultured in Dulbecco's modified Eagle's medium (DMEM; Gibco; Thermo Fisher Scientific, Inc.) supplemented with $10 \%$ (v/v) fetal bovine serum (Gibco; Thermo Fisher Scientific, Inc.).

Cell grouping. HCMECs were divided into the following five treatment groups: Control, HR, and APS-low (-L), -medium (-M) and -high (-H). Cells in the control group were cultured without any treatment. In the HR group, $200 \mu \mathrm{l}$ cells $\left(1 \times 10^{5} / \mathrm{ml}\right)$ were incubated with $1 \mathrm{mM} \mathrm{Na} \mathrm{S}_{2} \mathrm{O}_{4}$ for $4 \mathrm{~h}$ and cultured in DMEM for a further $24 \mathrm{~h}$. In the APS-L, -M and -H groups, cells were pretreated with 25,50 or $100 \mu \mathrm{g} / \mathrm{ml} \mathrm{APS}$, respectively, for $12 \mathrm{~h}$. Cells $\left(200 \mu \mathrm{l} ; 1 \times 10^{5} / \mathrm{ml}\right)$ were then incubated with $\mathrm{Na}_{2} \mathrm{~S}_{2} \mathrm{O}_{4}$ for $4 \mathrm{~h}$ and cultured in DMEM for a further $24 \mathrm{~h}$. The concentration range of APS used was selected according to the results of a pilot study that used a wider concentration range (data not presented).

Cell viability and apoptosis. Cells in the exponential growth phase were seeded in 96-well plates and cultured at $37^{\circ} \mathrm{C}$ and $5 \% \mathrm{CO}_{2}$ for $24 \mathrm{~h}$. Following treatment, $20 \mu \mathrm{l} \mathrm{MTT}(5 \mathrm{mg} / \mathrm{ml})$ was added to each well. After $4 \mathrm{~h}$, the culture media was discarded and replaced by $150 \mu \mathrm{l}$ dimethyl sulfoxide. After $10 \mathrm{~min}$ incubation, the absorbance was determined at $570 \mathrm{~nm}$ using an Infinite F200 microplate reader (Tecan Group, Ltd., Männedorf Switzerland). For cell apoptosis measurements, $200 \mu \mathrm{l}$ cells $\left(1 \times 10^{5} / \mathrm{ml}\right)$ were cultured in 6 -well plates, incubated with Hoechst and analyzed using a Hoechst apoptosis kit, according to the manufacturer's protocol.

Intracellular ROS levels. Cells were treated as described. Following treatment, $200 \mu \mathrm{l}$ cells $\left(1 \times 10^{5} / \mathrm{ml}\right)$ were washed with phosphate-buffered saline (PBS; Beyotime Institute of Biotechnology), then incubated with $20 \mu \mathrm{M}$ DCFH-DA in PBS for $2 \mathrm{~h}$. Subsequently, cells were examined with a fluorospectrophotometer (SPEX Fluorolog-2; Horiba, Ltd., Kyoto, Japan) at excitation and emission wavelengths of 340 and $520 \mathrm{~nm}$, respectively to measure the levels of intracellular ROS.

Intracellular $\mathrm{Ca}^{2+}$ measurements. Cells $\left(200 \mu \mathrm{l} ; 8 \times 10^{3} / \mathrm{ml}\right)$ were seeded onto 20 -mm coverslips in 6-well plates and cultured for $48 \mathrm{~h}$. Cells were then treated as described and cultured for a further $48 \mathrm{~h}$. Following incubation with $1 \mu \mathrm{l}$ Fura-2/AM and $499 \mu \mathrm{l} \mathrm{Ca}{ }^{2+}$ solution $(2 \mathrm{mM}$ ) for $30 \mathrm{~min}$, cells were washed three times with PBS. Cells were examined using the fluorospectrophotometer at excitation wavelengths of 340 and $380 \mathrm{~nm}$. The fluorescence intensity ratios at 340 and $380 \mathrm{~nm}$ were analyzed to determine the intracellular $\mathrm{Ca}^{2+}$ levels.

Intracellular MDA, SOD and NO measurements. Cells in the logarithmic growth phase were seeded in 6-well plates and cultured for $48 \mathrm{~h}$. Cells $\left(200 \mu \mathrm{l} ; 8 \times 10^{3} / \mathrm{ml}\right)$ were then treated as described and cultured for a further $48 \mathrm{~h}$. Cells were collected by centrifugation $(1,000 \mathrm{x} \mathrm{g}$ for $10 \mathrm{~min})$ and repeated freeze/thaw cycles were performed to effuse the cellular contents. The supernatant was collected and used to determine the expression of MDA, SOD and NO using assay kits, according to the manufacturer's protocols.

Expression levels of PI3K/p-AKT, Bcl-2 and Bax. Cells in the logarithmic growth phase were seeded in 6-well plates and cultured for $48 \mathrm{~h}$. The cells $\left(200 \mu \mathrm{l} ; 8 \times 10^{3} / \mathrm{ml}\right)$ were then treated as described and cultured for a further $48 \mathrm{~h}$. The cells were collected and lysed (Beyotime Institute of Biotechnology), and the lysates were centrifuged at 1,000 x g for 10 min to obtain the cellular protein. Protein concentration was determined using the BCA kit. Equal protein samples were loaded onto 10\% SDS-PAGE gels (40 V for $4 \mathrm{~h}$ ). The separated proteins were transferred onto a nitrocellulose membrane (Beyotime Institute of Biotechnology) and blocked (Beyotime Institute of Biotechnology). The 
membrane was then incubated with the PI3K, p-AKT, Bcl-2 and Bax primary rabbit anti-human monoclonal antibodies (1:100) at $4^{\circ} \mathrm{C}$ overnight, followed by incubation with goat anti-rabbit horseradish peroxidase-conjugated secondary $\operatorname{IgG}(\mathrm{H}+\mathrm{L})$ antibody [cat. no. A0208; Beyotime Institute of Biotechnology (dilution, 1:500)]. Reactive protein was detected with an enhanced chemiluminescence western blotting kit (Beyotime Institute of Biotechnology) and Quantity One software version 4.6.2 (Bio-Rad Laboratories, Inc., Hercules, CA, USA) on a ChemiDoc XRS gel imaging system (Bio-Rad Laboratories, Inc.).

Caspase- 3 activity. Cells in the logarithmic growth phase were seeded in 6-well plates and cultured for $48 \mathrm{~h}$. Cells (200 $\mu \mathrm{l}$; $8 \times 10^{3} / \mathrm{ml}$ ) were then treated as described and cultured for a further $48 \mathrm{~h}$. Cells were collected via centrifugation $(1,000 \mathrm{x} \mathrm{g}$ for $10 \mathrm{~min}$ ), lysed and analyzed following the addition of the substrates from the caspase- 3 assay kit, according to the manufacturer's protocol. Absorbance at $405 \mathrm{~nm}$ (Multiskan Spectrum; Thermo Fisher Scientific, Inc.) was used to determine caspase- 3 activity.

Statistical analysis. The paired Student's t-test was performed to analyzed the data and SPSS software (version 17.0; SPSS, Inc., Chicago, IL, USA) was used. Data are expressed as the mean \pm standard deviation. $\mathrm{P}<0.05$ was considered to indicate a statistically significant difference.

\section{Results}

Effect of APS on cell viability and apoptosis. The current study investigated the effect of treatment with $\mathrm{Na}_{2} \mathrm{~S}_{2} \mathrm{O}_{4}$ and APS on HCMEC viability (Fig. 1A) and apoptosis (Fig. 1B and C). Following Hoechst staining, apoptotic cells exhibited bright and white fluorescence (Fig. 1C). Compared with the control group (untreated HCMECs), treatment with $\mathrm{Na}_{2} \mathrm{~S}_{2} \mathrm{O}_{4}$ resulted in a significant reduction in cell viability $(\mathrm{P}=0.003)$ and a significant increase in the number of apoptotic cells $(\mathrm{P}=0.001)$. By contrast, APS treatment resulted in elevated cell viability and reduced apoptosis in a concentration-dependent manner. At the middle and high concentrations of APS, cell viability was significantly increased compared with the HR group $(\mathrm{P}=0.009$ and $\mathrm{P}=0.002$, respectively; Fig. $1 \mathrm{~A})$, possibly due to the reduced apoptosis levels.

Effect of APS on intracellular ROS activity and $\mathrm{Ca}^{2+}$ concentration. Fig. 2 indicates the ROS and $\mathrm{Ca}^{2+}$ levels in HCMEC treated with $\mathrm{Na}_{2} \mathrm{~S}_{2} \mathrm{O}_{4}$ (the HR group) and APS. ROS (Fig. 2A) and $\mathrm{Ca}^{2+}$ (Fig. 2B) levels in the HR group were significantly increased in comparison with the control group $(\mathrm{P}=0.001)$. When cells were treated with the middle and high doses of APS, the intracellular levels of ROS and $\mathrm{Ca}^{2+}$ were significantly reduced compared with the HR group (APS-M, $\mathrm{P}=0.016$ and APS-H, $\mathrm{P}=0.004$, and APS-M, $\mathrm{P}=0.027$ and APS- $\mathrm{H}, \mathrm{P}=0.005$, respectively). Thus, APS effected ROS and $\mathrm{Ca}^{2+}$ levels in a concentration-dependent manner.

Effect of APS on intracellular NO content. Intracellular NO levels were measured following treatment with $\mathrm{Na}_{2} \mathrm{~S}_{2} \mathrm{O}_{4}$ (the HR group) or APS (Fig. 3). NO levels in the HR group were observed to be reduced compared with the untreated cells $(\mathrm{P}=0.001)$. APS-L did not reverse the $\mathrm{Na}_{2} \mathrm{~S}_{2} \mathrm{O}_{4}$-induced decrease in ROS levels in the HR group. However, following treatment with the middle and high doses of APS, the NO level was significantly elevated compared with the HR group $(\mathrm{P}=0.07$ and $\mathrm{P}=0.002$, respectively), suggesting that APS can increase NO levels following HR injury of HCMECs.

Effect of APS on intracellular MDA content and SOD activity. MDA and SOD levels in HCMECs treated with $\mathrm{Na}_{2} \mathrm{~S}_{2} \mathrm{O}_{4}$ (the HR group) and various concentrations of APS are presented in Table I. Compared with the untreated cells, the MDA concentration in the HR group was significantly increased by $\sim 1.4$ fold $(\mathrm{P}=0.001)$. However, compared with the HR group, the level of MDA was significantly decreased when cells were pretreated with the three doses of APS ( $\mathrm{P}=0.008, \mathrm{P}=0.005$ and $\mathrm{P}=0.003$, respectively). As for SOD, the levels were significantly reduced in the HR group compared with the control group ( $\mathrm{P}=0.001)$. Additionally, compared with the HR group, APS pretreatment significantly increased the levels of SOD in a concentration-dependent manner $(\mathrm{P}=0.008, \mathrm{P}=0.002$ and $\mathrm{P}=0.002$, respectively).

Effect of APS on PI3K/p-AKT protein expression levels. Western blotting with qualitative and quantitative analysis was performed to evaluate the expression of $\mathrm{PI} 3 \mathrm{~K} / \mathrm{p}-\mathrm{AKT}$ in HCMECs following treatment with $\mathrm{Na}_{2} \mathrm{~S}_{2} \mathrm{O}_{4}$ (the HR group) and various concentrations of APS. As presented in Fig. 4, similar levels of AKT were observed in all groups, thus, AKT was used as the internal control of quantification of p-AKT levels. Reduced levels of PI3K and p-AKT were detected in the HR group compared with the control group ( $\mathrm{P}=0.001)$, suggesting the downregulation of PI3K levels and reduced phosphorylation of AKT. Following APS pretreatment at all three doses, the PI3K and p-AKT levels were significantly upregulated in a dose-dependent manner compared with the HR group (PI3K: APS-L, $\mathrm{P}=0.007$; APS-M, $\mathrm{P}=0.001$; and APS-H, $\mathrm{P}=0.001$ and $\mathrm{p}-\mathrm{AKT}$ : $\mathrm{P}=0.009, \mathrm{P}=0.001$ and $\mathrm{P}=0.001)$.

Effect of APS on Bcl-2 and Bax protein expression levels. The expression levels of Bcl-2 and Bax in HCMECs were determined by western blotting with qualitative and quantitative analysis (Fig. 5). Compared with control cells, the expression of $\mathrm{Bcl}-2$ in the HR group was significantly reduced $(\mathrm{P}=0.003)$. However, compared with the HR group, the middle and high doses of APS significantly increased the $\mathrm{Bcl}-2$ expression levels ( $\mathrm{P}=0.008$ and $\mathrm{P}=0.002$, respectively). As for Bax, its expression was significantly increased in the HR group $(\mathrm{P}=0.001)$. Following APS preconditioning, the high expression of Bax induced by odium dithionite was decreased by APS at all the three doses to a relatively low level (all $\mathrm{P}=0.001$ ).

Effect of APS on caspase-3 activity. The activity of caspase-3 in HCMEC was determined using a caspase- 3 assay kit and the results are presented in Fig. 6 . The activity of caspase-3 was significantly increased by $\mathrm{Na}_{2} \mathrm{~S}_{2} \mathrm{O}_{4}$ treatment (the HR group) compared with the control cells $(\mathrm{P}=0.001)$. Notably, the middle and high doses of APS significantly reduced the high 
A

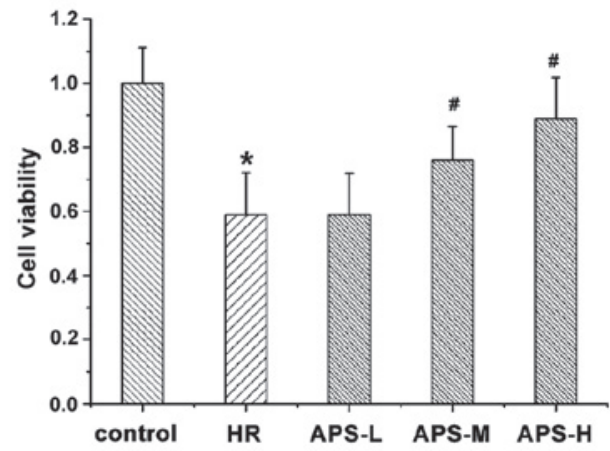

C

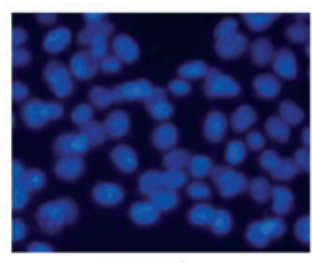

control

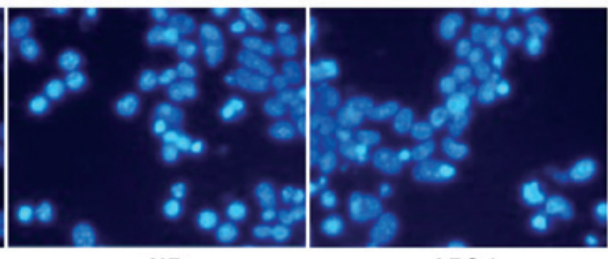

HR

APS-L

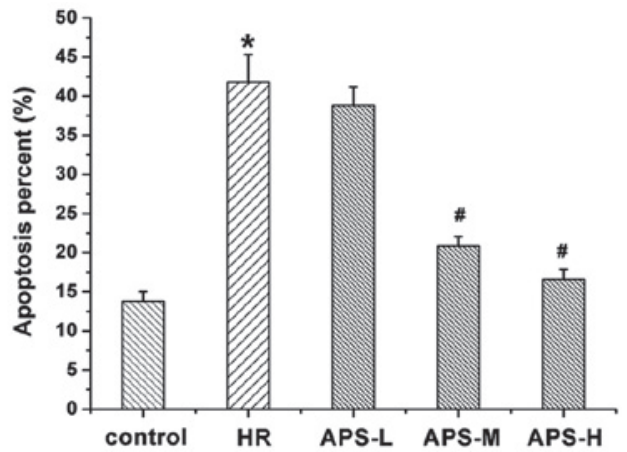

Figure 1. Cell viability and apoptosis of human cardiac microvascular endothelial cells. (A) Cell viability was determined using a methylthiazolyl tetrazolium assay following treatment with $\mathrm{Na}_{2} \mathrm{~S}_{2} \mathrm{O}_{4}$ (the $\mathrm{HR}$ group), and 25, 50 or $100 \mu \mathrm{g} / \mathrm{ml}$ APS (APS-L, APS-M and APS-H groups, respectively). Cells with no treatment served as the control. (B and C) Apoptosis was measured under the same treatment conditions (Hoechst staining; magnification, $\mathrm{x} 200$ ). Data are presented as the mean \pm standard deviation $(\mathrm{n}=3)$. ${ }^{*} \mathrm{P}<0.01$ vs. the control group; $\mathrm{P}<0.01$ vs. the HR group. HR, hypoxia/reoxygenation; APS, Astragalus polysaccharide; -L, -low dose; -M, -medium dose; -H, -high dose.
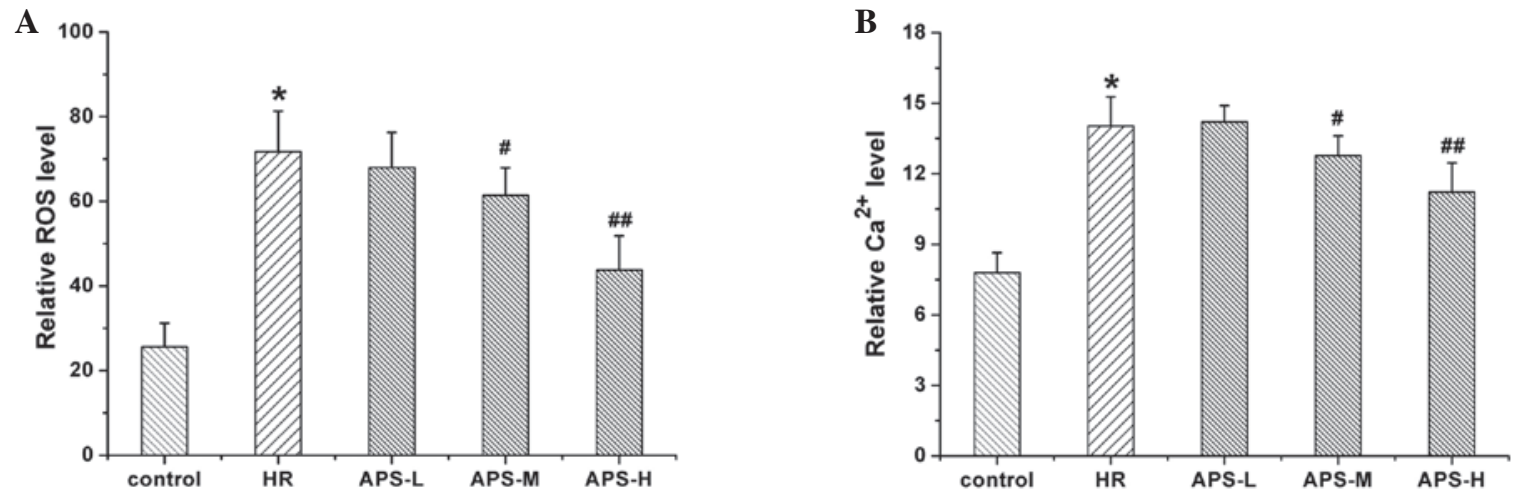

Figure 2. (A) ROS and (B) $\mathrm{Ca}^{2+}$ levels in human cardiac microvascular endothelial cells following treatment with $\mathrm{Na}_{2} \mathrm{~S}_{2} \mathrm{O}_{4}$ (the $\mathrm{HR}$ group) and 25,50 or $100 \mu \mathrm{g} / \mathrm{ml}$ APS (APS-L, APS-M and APS-H groups, respectively). Cells with no treatment served as the control. Data are presented as the mean \pm standard deviation ( $\mathrm{n}=3$ ). ${ }^{*} \mathrm{P}<0.01$ vs. the control group; ${ }^{*} \mathrm{P}<0.05,{ }^{\# \#} \mathrm{P}<0.01$ vs. the HR group. ROS, reactive oxygen species; HR, hypoxia/reoxygenation group; APS, Astragalus polysaccharide; -L, -low dose; -M, -medium dose; -H, -high dose.

activity of caspase-3 induced by $\mathrm{Na}_{2} \mathrm{~S}_{2} \mathrm{O}_{4}$ compared with the $\mathrm{HR}$ group in a concentration-dependent manner $(\mathrm{P}=0.003$ and $\mathrm{P}=0.001$, respectively).

\section{Discussion}

The vascular endothelium is composed of a monolayer of endothelial cells that secrete a variety of vasoactive substances via autocrine and paracrine mechanisms, targeting various cell types, including vascular smooth muscle cells and peripheral white blood cells. Therefore, the vascular endothelium not only serves as a physiological barrier, it is also important in antithrombosis and inhibition of inflammation of the vascular wall. HR-induced injury damages the vascular endothelium and, thus, impairs the function of VECs. Using MTT and Hoechst assays, the current study demonstrated that HCMECs are protected by APS, particularly at high doses, following HR-induced injury.

Free radicals are important in the endothelial injury induced by HR. ROS produced by HR stimuli penetrate the cellular membrane causing lipid peroxidation and cellular damage. The stable internal and external environments of the vessels are disrupted by ROS, resulting in VEC injury. ROS-induced endothelial injury is associated with elevated levels of intracellular free $\mathrm{Ca}^{2+}$, an important second messenger in cells. An excess of $\mathrm{Ca}^{2+}$ promotes the hydrolysis of phospholipase into noxious substances, including fatty acid and leukotriene, which are harmful to cells and promote the decomposition of cytoskeletal components, leading to cellular damage. Dysregulation of $\mathrm{Ca}^{2+}$ levels in VECs changes the expression levels of eNOS and induces cell apoptosis (15). Additionally, increases of $\mathrm{Ca}^{2+}$ levels exceeding the normal 


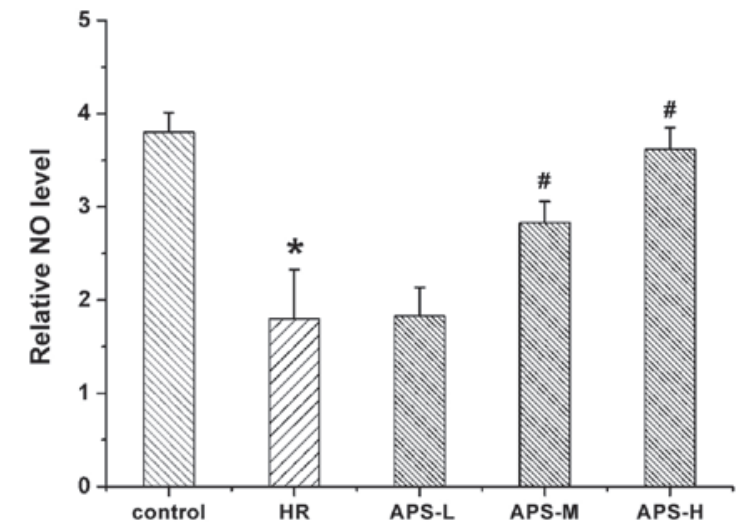

Figure 3. NO levels in human cardiac microvascular endothelial cells following treatment with $\mathrm{Na}_{2} \mathrm{~S}_{2} \mathrm{O}_{4}$ (the HR group) and 25,50 or $100 \mu \mathrm{g} / \mathrm{ml}$ APS (APS-L, APS-M and APS-H groups, respectively). Cells with no treatmen served as the control. Data are presented as the mean \pm standard deviation $(\mathrm{n}=3) .{ }^{*} \mathrm{P}<0.01$ vs. the control group, ${ }^{\#} \mathrm{P}<0.01$ vs. the HR group. NO, nitric oxide; HR, hypoxia/reoxygenation; APS, Astragalus polysaccharide; -L, -low dose; -M, -medium dose; -H, -high dose.

threshold in cells facilitates the accumulation of ROS. ROS accumulation reduces the activity of eNOS, which catalyzes NO production under normal physiological conditions. NO is a vascular protective factor produced by endothelial cells. During oxidative stress, the majority of superoxide anions inhibit the biological activity of eNOS, thus reducing the production and activity of NO. The decreased NO level and biological activity initiates vasodilatation and damage to the function of VECs. The activation of AKT in VECs may increase the release of $\mathrm{NO}$ and maintain the integrity of the functional layer of VECs (16).

A previous report demonstrated that Radix Astragali protects endothelial cells from apoptosis via the inhibition of ROS (10). Zhu et al (17) observed that 10-50 $\mu \mathrm{g} / \mathrm{ml}$ APS significantly inhibited ROS production induced by tumor necrosis factor- $\alpha$ in HCMECs. Additionally, APS was demonstrated to ameliorate diabetes in palmitate-induced KKAy diabetic mice via the ROS pathway (18). The current study investigated the detailed mechanisms involved in the protection of HCMECs from HR by APS. It was observed that APS protected HCMECs from HR-induced injury by significantly decreasing the levels of ROS and $\mathrm{Ca}^{2+}$, and enhancing the levels of NO. It was also demonstrated that APS was able to protect VECs from HR-induced injury via regulating the levels of vasoactive substances and oxidizing materials, including ROS.

Excessive accumulation of ROS directly results in lipid peroxidation of the cell membrane, with MDA produced as the typical by-product. The levels of MDA are associated with the severity of oxidative stress experienced by cells. SOD is an endogenous antioxidative enzyme that breaks down intracellular ROS when cells are exposed to an external stress. Thus, changes to the levels of intracellular MDA and SOD can be used to indirectly reflect the degree of cellular oxidative damage. It was previously reported that APS treatment reduced ROS and MDA levels, and increased the expression levels of SOD in EA.hy926 cells with bronchopulmonary dysplasia (19). Similarly, the present study observed that APS treatment decreased the MDA levels and increased the SOD levels in HCMECs with HR injury.
The PI3K/AKT signaling pathway regulates various biological functions of cells, including cell growth, proliferation and adhesion. Intracellular accumulation of ROS inhibits the PI3K/AKT signaling pathway and induces cell apoptosis $(2,3)$. Specifically, the activation of PI3K results in the recruitment and phosphorylation of $\mathrm{AKT}$, and affects the target proteins of this pathway, including Bcl-2, Bax and caspase-3, via a signaling cascade (4). The upregulation of PI3K/AKT signaling may inhibit the apoptosis of HCMECs and the endothelial dysfunction induced by HR (20). Activation of the PI3K/AKT pathway may also prevent HR-induced apoptosis of myocardium microvascular endothelial cells (21). It was previously indicated that the PI3K/AKT signaling pathway is important in the regulation of endothelial cell apoptosis, thus, APS may exert cytoprotective effects via regulation of PI3K/AKT signaling. Cao et al (22) observed that APS inhibits the apoptosis of myocardial cells and reduces heart failure in a doxorubicin-induced mouse model via the suppression of AKT activity and the reduction of ROS levels. Ye et al (23) demonstrated that the proliferation of MDA-MB-468 breast cancer cells was arrested by regulating AKT phosphorylation at Thr308 and Ser473. Additionally, extracts of Radix Astragali attenuated cytokine-induced keratinocyte damage via the intracellular ROS level and the PI3K/AKT pathway (24). Astragaloside was previously demonstrated to inhibit myocardial cell apoptosis induced by doxorubicin via a reduction in ROS levels, which was associated with the PI3K/AKT signaling pathway (25). In the current study, APS attenuated HR-induced HCMEC damage via upregulation of PI3K expression and increased phosphorylation of AKT. This suggests that APS protects HCMECs from HR injury through regulation of the PI3K/AKT signaling pathway.

The accumulation of ROS enhances apoptosis in endothelial cells (26). The Bcl-2 protein family is important in the process of apoptosis. In particular, $\mathrm{Bcl}-2$ is the major anti-apoptotic protein. It binds to the pro-apoptotic protein, Bax, forming heterodimers in the outer mitochondrial membrane; this reduces the release of caspase from the mitochondria, leading to inhibition of cell apoptosis. Caspases are essential proteins in cell apoptosis; in particular, caspase- 3 is the crucial effector and a focal point of the apoptosis pathway. The apoptosis of HCMECs induced by HR was associated with decreased expression levels of Bcl-2, and increased expression levels of Bax and activated caspase-3 (27). Xiao et al (28) reported that treatment with $100-200 \mu \mathrm{g} / \mathrm{ml}$ APS decreased the apoptosis of HL-60 cells by inhibiting the activity of caspase-3. In the current study, it was observed that APS protected HCMECs from HR-induced injury by upregulating $\mathrm{Bcl}-2$ expression levels, downregulating Bax expression levels and inhibiting caspase- 3 activity. Additionally, the current study demonstrated that HCMEC protection by APS was concentration-dependent. The higher dose of APS was associated with the greatest change in ROS, $\mathrm{Ca}^{2+}$, NO, MDA, SOD, PI3K/AKT, Bcl-2 and Bax levels, as well as caspase- 3 activity.

Notably, the lack of antagonist or agonist use to intervene in key signaling mechanisms was a limitation of the present study, and should be taken into consideration when developing protocols for future studies. 
Table I. MDA and SOD levels in human cardiac microvascular endothelial cells treated with $\mathrm{Na}_{2} \mathrm{~S}_{2} \mathrm{O}_{4}$ and various concentrations of APS.

\begin{tabular}{lcc}
\hline Group & $\begin{array}{c}\text { MDA, } \\
\mathrm{mM} / \mathrm{mg} \text { protein }\end{array}$ & $\begin{array}{c}\text { SOD, } \\
\mathrm{U} / \mathrm{l} \text { protein }\end{array}$ \\
\hline Control & $1.80 \pm 0.03$ & $19.10 \pm 0.67$ \\
HR & $4.26 \pm 0.04^{\mathrm{a}}$ & $9.14 \pm 0.41^{\mathrm{a}}$ \\
APS-L & $3.90 \pm 0.03^{\mathrm{b}}$ & $11.81 \pm 0.26^{\mathrm{b}}$ \\
APS-M & $3.20 \pm 0.04^{\mathrm{b}}$ & $16.05 \pm 0.33^{\mathrm{b}}$ \\
APS-H & $2.79 \pm 0.05^{\mathrm{b}}$ & $17.99 \pm 0.32^{\mathrm{b}}$ \\
\hline
\end{tabular}

Cells with no treatment served as the control group. The APS groups, APS-L, APS-M, and APS-H, were treated with 25, 50 and $100 \mu \mathrm{g} / \mathrm{ml}$, respectively. Data are presented as the mean \pm standard deviation ( $\mathrm{n}=6$ ). ${ }^{\mathrm{a}} \mathrm{P}<0.01$ vs. control group, ${ }^{\mathrm{b}} \mathrm{P}<0.01$ vs. HR group. MDA, malondialehyde; SOD, superoxide dismutase; APS, Astragalus polysaccharide; HR, hypoxia/reoxygenation group; -L, -low dose; -M, -medium dose; - $\mathrm{H}$, -high dose.
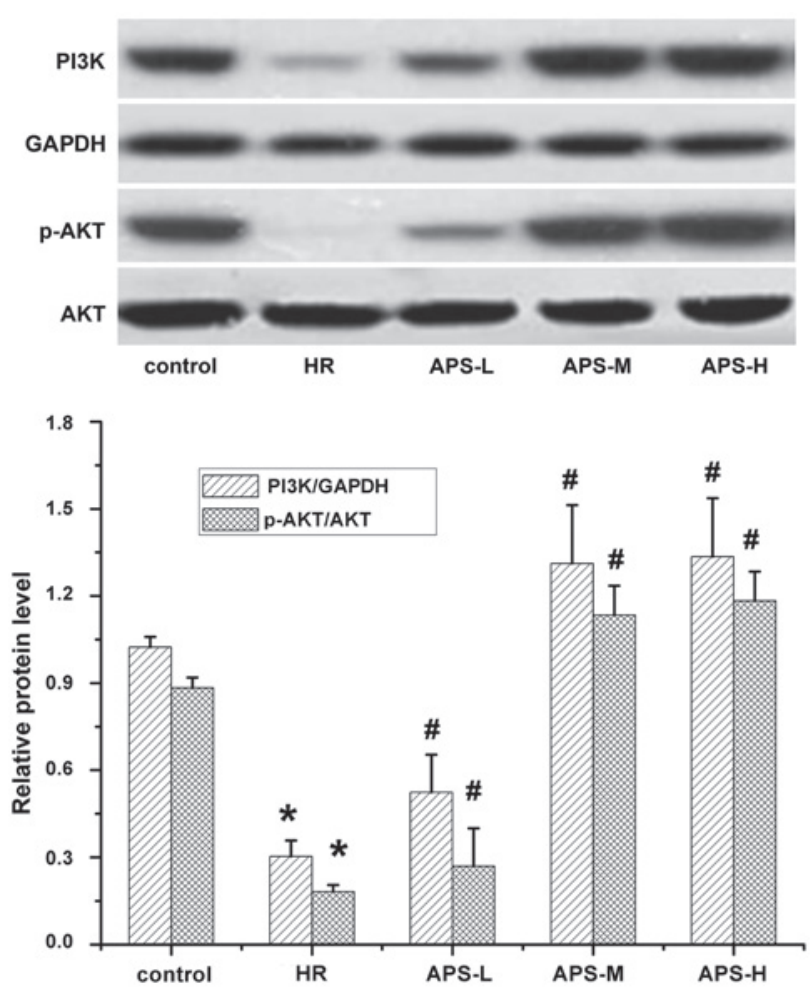

Figure 4. Western blot analysis of PI3K/p-AKT expression levels in human cardiac microvascular endothelial cells treated with $\mathrm{Na}_{2} \mathrm{~S}_{2} \mathrm{O}_{4}$ (the HR group) and 25,50 or $100 \mu \mathrm{g} / \mathrm{ml}$ APS (APS-L, APS-M and APS-H groups, respectively). Cells with no treatment served as the control. GAPDH was used as the internal control. Data are presented as the mean \pm standard deviation $(\mathrm{n}=3)$. ${ }^{\text {}} \mathrm{P}<0.01$ vs. the control group, ${ }^{*} \mathrm{P}<0.01$ vs. the HR group. PI3K, phosphatidylinositol 3-kinase; p-AKT, phosphorylated-protein kinase B; HR, hypoxia/reoxygenation; APS, Astragalus polysaccharide; -L, -low dose; -M, -medium dose; -H, -high dose.

In conclusion, APS protected HCMECs from HR-induced injury by reducing the levels of ROS, $\mathrm{Ca}^{2+}$, MDA and Bax, increasing the levels of NO, SOD, Bcl-2 and PI3K, enhancing the phosphorylation of AKT, and inhibiting

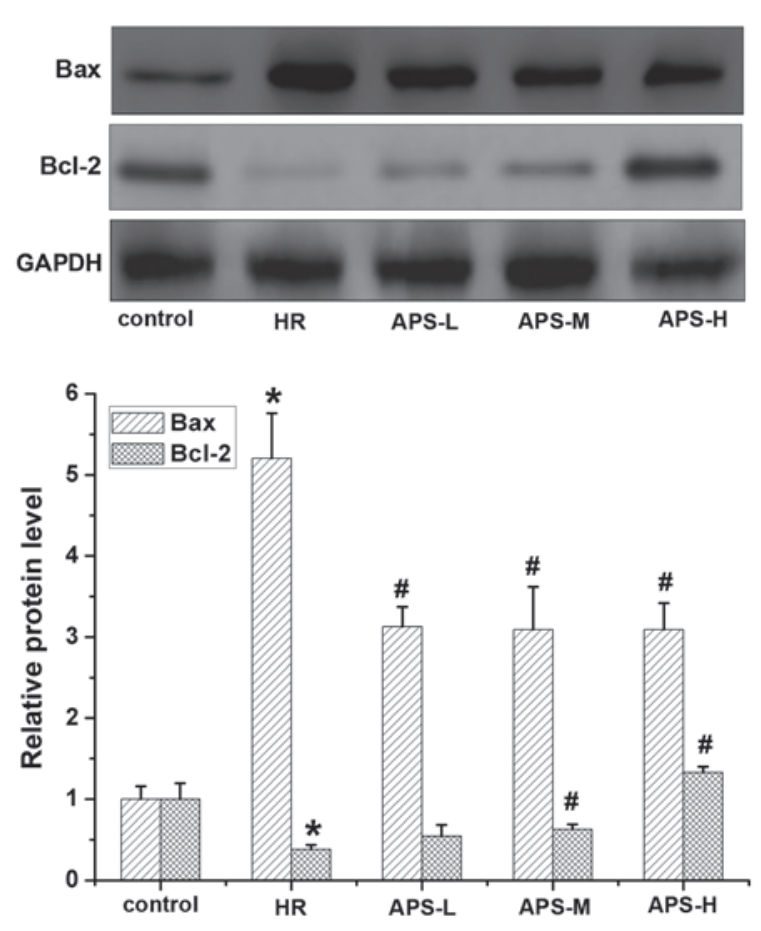

Figure 5. Western blot analysis of Bcl-2 and Bax expression levels in human cardiac microvascular endothelial cells treated with $\mathrm{Na}_{2} \mathrm{~S}_{2} \mathrm{O}_{4}$ (the $\mathrm{HR}$ group) and 25,50 or $100 \mu \mathrm{g} / \mathrm{ml}$ APS (APS-L, APS-M and APS-H groups, respectively). Cells with no treatment served as the control. GAPDH was used as the internal control. Data are presented as the mean \pm standard deviation $(n=3)$. ${ }^{*} \mathrm{P}<0.01$ vs. the control group; ${ }^{*} \mathrm{P}<0.01$ vs. the HR group. Bax, $\mathrm{Bcl}-2$-associated $\mathrm{X}$ protein; Bcl-2, B-cell lymphoma-2; HR, hypoxia/reoxygenation; APS, Astragalus polysaccharide; -L, -low dose; -M, -medium dose; - $\mathrm{H}$, -high dose.

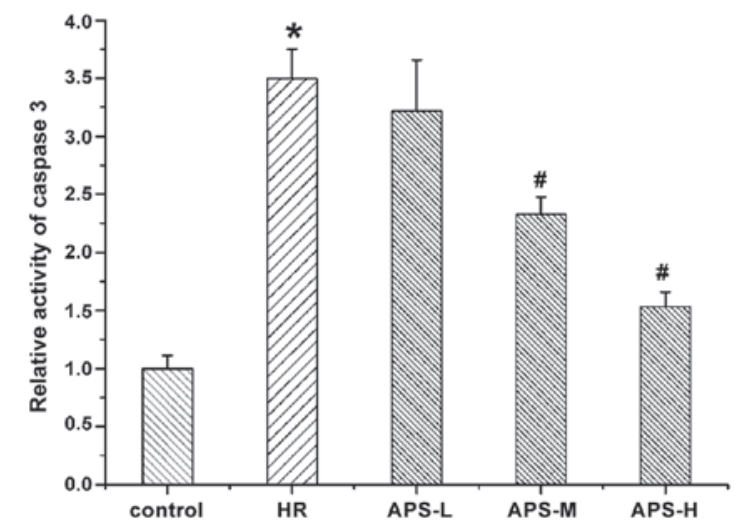

Figure 6. Caspase-3 activity in human microvascular endothelial cells treated with $\mathrm{Na}_{2} \mathrm{~S}_{2} \mathrm{O}_{4}$ (the HR group) and 25,50 or $100 \mu \mathrm{g} / \mathrm{ml}$ APS (APS-L, APS-M and APS-H groups, respectively). Cells with no treatment served as the control. Data are presented as the mean \pm standard deviation $(n=3)$. ${ }^{*} \mathrm{P}<0.01$ vs. the control group; ${ }^{\#} \mathrm{P}<0.01$ vs. the HR group. HR, hypoxia/reoxygenation; APS, Astragalus polysaccharide; -L, -low dose; -M, -medium dose; -H, -high dose.

the activity of caspase-3. Furthermore, APS acted in a concentration-dependent manner, providing greater protection at higher doses. These results may provide an insight into the mechanisms associated with HR-induced injury of HCMECs and the protective effect of APS. The findings of the current study may serve as a guideline for the clinical application of APS and the treatment of HR-induced injury. 


\section{Acknowledgements}

The authors are grateful for the financial support from the National Natural Science Foundation of China (nos. 81102573 and 81273692).

\section{References}

1. Mangge H, Becker K, Fuchs D and Gostner JM: Antioxidants, inflammation and cardiovascular disease. World J Cardiol 6: 462-477, 2014.

2. Cao G, Cai H, Cai B and Tu S: Effect of 5-hydroxymethylfurfural derived from processed Cornus officinalis on the prevention of high glucose-induced oxidative stress in human umbilical vein endothelial cells and its mechanism. Food Chem 140: 273-279, 2013

3. Zhang J, Wang Z, Zuo G, Li B, Zhang J, Tian N and Chen S: Low shear stress induces human vascular endothelial cell apoptosis by activating Akt signal and increasing reactive oxygen species. Nan Fang Yi Ke Da Xue Xue Bao 33: 313-317, 2013.

4. Hu L, Sun Y and Hu J: Catalpol inhibits apoptosis in hydrogen peroxide-induced endothelium by activating the PI3K/Akt signaling pathway and modulating expression of $\mathrm{Bcl}-2$ and Bax. Eur J Pharmacol 628: 155-163, 2010.

5. Ginter E, Simko V and Panakova V: Antioxidants in health and disease. Bratisl Lek Listy 115: 603-606, 2014.

6. Zhang X, Xu X and Wang N: Progress of studies on protective mechanism of Radix Astragali in vascular endothelial cells. Chinese Pharm J 48: 1526-1530, 2013.

7. Hai-Yan Z, Yong-Hong G, Zhi-Yao W, Bing X, Ai-Ming W, Yan-Wei X, Bei L, Li-Xia L and Li-Xin C: Astragalus polysaccharide suppresses the expression of adhesion molecules through the regulation of the p38 MAPK signaling pathway in human cardiac microvascular endothelial cells after ischemia-reperfusion injury. Evid Based Complement Alternat Med 2013: 280493, 2013.

8. Xu B, Zhu H, Gao Y, Liu B, Zhu L and Chen L: Influences of Astragalus polysaccharides on genetic transcription of P-selectin and E-selectin in human cardiac microvascular endothelial cells after ischemia-reperfusion injury. J Beijing Univ Tradit Chin Med 34: 177-180, 2011.

9. Yin Y, Li P, Lu G, Liang J and Zhao F: Protective effects of APS-A3 on blood vessel endothelium function induced by paraoxon. Lishizhen Med Mater Med Res 22: 583-585, 2011.

10. Li T, Chen L, Li Q, Zhou Y, Tang H and Cheng S: The protective effects of tetramethylpyrazine (TMP) combined with Astragalus polysaccharides (APS) on vascular endothelial cells (VECs). China J Tradit Chin Med Pharm 26: 2672-2675, 2011.

11. Zhong Y, Cheng C, Huang H, Li A, Liu B and Liu S: Astragalus polysaccharides protects advanced glycation end-products induced endothelial cells apoptosis. Clin Med Eng 21: 18-20, 2014.

12. Xu H, Wu Q, Xie X and Kong D: Effect of Astragalus polysaccharides on peripheral endothelial progenitor cells via PI3K/Akt/eNOS signal pathway in patients with type 2 diabetes. J Clin Rehabilitative Tissue Eng Res 15: 4272-4276, 2011.

13. Wang S, Feng Y, Wang L, Wang Y, Xu D and Ruan K: The effect of polysaccharide from Radix Astragali on cells survival against oxygen glucose deprivation and phosphorylation of Akt. Pharm Biotechnol 18: 288-290,2011.

14. Zhu H, Chen L and Zhu L: Effect of astragalus polysaccharides on expression of ICAM-1 and VCAM-1 in human cardiac microvascular endothelial cells after hypoxia and reoxygenation. Liaoning J Tradit Chinese Med 35: 293-295, 2008.
15. Suriyo T, Watcharasit P, Thiantanawat A and Satayavivad J: Arsenite promotes apoptosis and dysfunction in microvascular endothelial cells via an alteration of intracellular calcium homeostasis. Toxicol In Vitro 26: 386-395, 2012.

16. Mukai Y, Shimokawa H, Matoba T, Hiroki J, Kunihiro I, Fujiki T and Takeshita A: Acute vasodilator effects of HMG-CoA reductase inhibitors: Involvement of PI3-kinase/Akt pathway and Kv channels. J Cardiovasc Pharmacol 42: 118-124, 2003.

17. Zhu YP, Shen T, Lin YJ, Chen BD, Ruan Y, Cao Y, Qiao Y, Man Y, Wang S and Li J: Astragalus polysaccharides suppress ICAM-1 and VCAM-1 expression in TNF- $\alpha$-treated human vascular endothelial cells by blocking NF-kB activation. Acta Pharmacol Sin 34: 1036-1042, 2013.

18. Liu M, Qin J, Hao Y, Liu M, Luo J, Luo T and Wei L: Astragalus polysaccharide suppresses skeletal muscle myostatin expression in diabetes: Involvement of ROS-ERK and NF-kB pathways. Oxid Med Cell Longev 2013: 782497, 2013.

19. Huang WM, Liang YQ, Tang LJ, Ding Y and Wang XH: Antioxidant and anti-inflammatory effects of Astragalus polysaccharide on EA.hy926 cells. Exp Ther Med 6: 199-203, 2013.

20. Zuo H, Liao D, Lin L, Zhang R and Li X: Resveratrol attenuates hypoxia-reperfusion injury induced rat myocardium microvascular endothelial cell dysfunction through upregulating PI3K/Akt/SVV pathways. Zhonghua Xin Xue Guan Bing Za Zhi 42: 670-674, 2014 (In Chinese).

21. Su C, Xia T, Ren S, Qing S, Jing D, Lian H, Bin Q, Yuan Z and Xiang Z: Effect of diazoxide preconditioning on cultured rat myocardium microvascular endothelial cells against apoptosis and relation of PI3K/Akt pathway. Balkan Med J 31: 83-87, 2014.

22. Cao Y, Ruan Y, Shen T, Huang X, Li M, Yu W, Zhu Y, Man Y, Wang S and Li J: Astragalus polysaccharide suppresses doxorubicin-induced cardiotoxicity by regulating the PI3k/Akt and p38MAPK pathways. Oxid Med Cell Longev 2014: 674219, 2014.

23. Ye MN, Chen HF, Zhou RJ and Liao MJ: Effects of Astragalus polysaccharide on proliferation and Akt phosphorylation of the basal-like breast cancer cell line. Zhong Xi Yi Jie He Xue Bao 9: 1339-1346, 2011 (In Chinese).

24. Kim BH, Oh I, Kim JH, Jeon JE, Jeon B, Shin J and Kim TY: Anti-inflammatory activity of compounds isolated from Astragalus sinicus L. in cytokine-induced keratinocytes and skin. Exp Mol Med 46: e87, 2014.

25. Jia Y, Zuo D, Li Z, Liu H, Dai Z, Cai J, Pang L and Wu Y: Astragaloside IV inhibits doxorubicin-induced cardiomyocyte apoptosis mediated by mitochondrial apoptotic pathway via activating the PI3K/Akt pathway. Chem Pharm Bull (Tokyo) 62: 45-53, 2014.

26. Ge GH, Dou HJ, Yang SS, Ma JW, Cheng WB, Qiao ZY, Hou YM and Fang WY: Glucagon-like peptide-1 protects against cardiac microvascular endothelial cells injured by high glucose. Asian Pac J Trop Med 8: 73-78, 2015.

27. Velotta JB, Kimura N, Chang SH, Chung J, Itoh S, Rothbard J, Yang PC, Steinman L, Robbins RC and Fischbein MP: $\alpha \mathrm{B}$-crystallin improves murine cardiac function and attenuates apoptosis in human endothelial cells exposed to ischemia-reperfusion. Ann Thorac Surg 91: 1907-1913, 2011.

28. Xiao B, Xu Y, He H, Jiang QL, Li SY, Shu HY, Liang EY, Yi ZS, Ye JY, Huang LF et al: Anti-apoptotic effect of Astragalus polysaccharide on myeloid cells. Zhongguo Shi Yan Xue Ye Xue Za Zhi 21: 1243-1247, 2013 (In Chinese). 